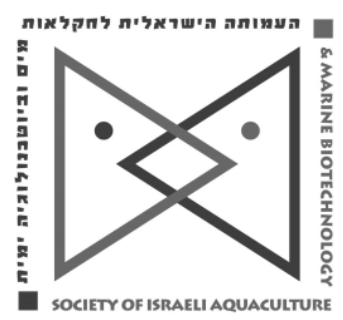

The IJA appears exclusively as a peer-reviewed on-line open-access journal at http://www.siamb.org.il. To read papers free of charge, please register online at registration form.

Sale of IJA papers is strictly forbidden.

\title{
Effect of Dietary Surfactin Supplementation on Parameters Related to Lipid Metabolism of Orange- Spotted Grouper
}

\author{
Shao-Wei Zhai ${ }^{1 *}$, Xiu-Wen Sun ${ }^{1}$, Xue-Hao Chen ${ }^{1,2}$ \\ ${ }^{1}$ Fisheries College of Jimei University, China \\ ${ }^{2}$ Engineering Research Center of the Modern Industry Technology for Eel, \\ Ministry of Education, China \\ Keywords: Surfactin; orange-spotted grouper; lipid metabolism
}

\begin{abstract}
This trial was conducted to investigate the effects of dietary surfactin supplementation on parameters related to lipid metabolism of orange-spotted grouper (Epinephelus coioides) juveniles. Three hundred and sixty fish were randomly divided into 6 treatment groups, and fed dietary surfactin levels: S0 (control group), S25, S50, S100, S150, and $\mathrm{S} 200 \mathrm{mg} / \mathrm{kg}$, respectively. Four replicates with 15 fish per tank were randomly assigned to each group. The trial period was 56 days. The lipid levels in serum, liver, and whole fish, and some lipid metabolism enzymes in the liver were measured. When compared to fish fed no surfactin, fish fed diets supplemented with surfactin presented lower levels of total cholesterol, triglyceride, low-density lipoprotein cholesterol, and higher levels of high-density lipoprotein cholesterol in serum; lower lipid levels in whole fish and liver (only 100 and $150 \mathrm{mg} / \mathrm{kg}$ surfactin groups) were observed. Dietary $100 \mathrm{mg} / \mathrm{kg}$ surfactin supplementation had the most influence on lipids level in serum, whole fish, and liver of orange-spotted grouper juveniles. Lower levels of fatty acid synthetase and higher activity of hepatic lipase and lipoprotein (lipase in liver) were affected only by $100 \mathrm{mg} / \mathrm{kg}$ surfactin supplementation in diet. The levels of acetyl CoA carboxylase were similar in all groups. This suggests that appropriate supplementation levels of surfactin in the diet of orange-spotted grouper juveniles might have beneficial effects on lipid metabolism to improve fish health status.
\end{abstract}

\footnotetext{
* Corresponding author. Tel: +86-592-6181420, Fax: +86-592-6181476. e-mail: shaoweizhai@hotmail.com
} 


\section{Introduction}

Dietary formulations in aquaculture have tended to exhibit an upward trend in dietary lipid as this has successfully increased weight gains (Tocher, 2003). Increasing dietary lipid above the minimum level will support higher growth rates due to the simple fact that lipids supply twice as much energy per unit mass, compared to other dietary energy sources, and therefore more energy can be supplied in the feed per unit mass, a phenomenon often referred to as "protein sparing". However, an upper limit will be reached where the biochemical and physiological capacities of the animal to digest and/or metabolize dietary lipid are exceeded, leading to reduced digestibility and unwanted deposition of lipid in the liver, peritoneal cavity, or other tissues (Martinez-Rubio et al., 2013). Increased liver lipid deposition may have unwanted physiological effects such as the development of fatty liver pathology in marine fish (Caballero et al., 1999), which may be associated with increased lipid peroxidation and impaired liver function and necrosis (Craig et al., 1999). This poses a constant and serious threat to marine fish and has resulted in a significant economic loss in aquaculture.

Feed emulsifiers (bile acid or lecithin and mixture combination of both) have been used as anti-fat liver factors in aquaculture. Their characteristics include free solubility in water, surface activity (lowering of surface tension), and micelle formation. These emulsifiers serve to solubilize or emulsify fats to make them more digestible, and have a beneficial effect on growth and hepatic health in aquatic animals (Coutteau et al., 1997; Kim et al., 2007; Sun et al., 2014).

To date, the source of emulsifiers has been from animal or plant byproducts. The emulsifiers from microorganisms are seldom reported in aquatic animals. Surfactin, an efficient biosurfactant produced by several strains of Bacillus subtilis, is a cyclic lipoheptapeptide containing seven amino acids and a $\beta$-hydroxyl fatty acid. Due to its amphiphilic structure, it shows special surface, interface, and membrane-active properties (Seydlova and Svobodova, 2008; Liu et al., 2010). Compared with other emulsifiers, surfactin has some unique advantages such as lower toxicity, higher biodegradability, and effectiveness at extreme temperatures or $\mathrm{pH}$ values (Seydlova and Svobodova, 2008; Liu et al., 2010; Chen et al., 2015). The effect of oral administration of surfactin on lowering serum lipids have been reported in rats (Tani et al., 2006; Sahnoun et al., 2014; Ayed et al., 2015; Sanjukta et al., 2016), weaned pigs (Du et al., 2011), tilapia (Oreochromis niloticus)(Zhai et al., 2015a) and Chinese soft-shelled turtle (Pelodiscus sinensis) (Zhai et al., 2015b). However, little information about surfactin application in marine fish was available. Dietary surfactin supplementation in marine fish might have some effects on lipid metabolism and be beneficial in a farming context. The purpose of this study was to investigate whether dietary surfactin supplementation produces any beneficial effects on lipid levels in serum, liver, and whole fish, and some lipid metabolism enzymes in liver of a marine fish species, orange-spotted grouper (Epinephelus coioides). All these belong to the family of Serranidae that have been in the focus of mariculture in Southeast Asia, especially in China (Pierre et al. 2008; Li et al., 2013).

\section{Materials and Methods}

Fish source and rearing conditions. Orange-spotted grouper juveniles were purchased from XiaoDeng Aquatic Science and Technology Co Ltd of Xiamen (Fujian Province, China). After the fish were transported to the marine lab of Jimei University, one thousand fish were held in two plastic tanks $(60 \mathrm{~cm}$ diameter, $100 \mathrm{~cm}$ height, $800 \mathrm{~L}$ water volume), and fed the basal diet twice daily for 2 weeks during the adaptation period. Filtered seawater was supplied to the culture system with additional aeration provided by an air pump. $30-50 \%$ of the water was changed daily. Uneaten pellets and feces were siphoned out before each meal. Water quality was monitored twice weekly with a multiparameter photome (HI9804N, HANNA, Baranzate, MI, Italy). The values of dissolved oxygen was 6 to $8 \mathrm{mg} / \mathrm{L}$, $\mathrm{pH}$ was 8.0 to 8.2 , and ammonia- $\mathrm{N}$ was $<0.2 \mathrm{mg} / \mathrm{L}$. Water temperature ranged from $26-28^{\circ} \mathrm{C}$. Water quality was the same during both the adaptation period and throughout the trial period. After an adaptation period, the fish were kept in 24 rectangular aquaria $(75 \mathrm{~cm} \times 55 \mathrm{~cm} \times 60 \mathrm{~cm})$. The water volume of each 
aquarium was about $130 \mathrm{~L}$. Fish were fed to satiation three times daily (at 8:00 h, 13:00 $\mathrm{h}$ and 18:00 h).

Experimental design. After a 2 week adaptation period to the experimental conditions, 360 juvenile orange-spotted grouper $(46.67 \pm 0.07 \mathrm{~g}$; mean \pm SD) were selected and randomly divided into six treatment groups with four replicates in each group and 15 fish in each replicate. Fish were fed diets with the following surfactin levels: S0 (control group), S25, S50, S100, S150, and S200 mg/kg, respectively. The trial continued for 56 days.

Experimental diets. The basal diet was composed of fish meal $42.0 \%$, shrimp meal $3.0 \%$, soybean meal $27.0 \%$, wheat flour $19.9 \%$, fish oil $2.0 \%$, soybean oil $2.0 \%$, lecithin $2.0 \%$, vitamin premix $0.3 \%$, mineral premix $0.5 \%$, choline chloride $0.3 \%$, and $\mathrm{Ca}\left(\mathrm{H}_{2} \mathrm{PO}_{4}\right)_{2} 1.0 \%$. Nutritional levels of the basal diet were dry matter $92.76 \%$, crude protein $47.73 \%$, lipid $10.28 \%$, and ash $10.15 \%$.

Six experimental diets were formulated to contain various concentrations of surfactin. The different levels of surfactin (provided by Fujian Zhengyuan Feed Co., Ltd., Putian, China) were supplemented in the basal diet. All feed ingredients were thoroughly mixed and cold pelleted with a laboratory pelleting machine using a $2.5-\mathrm{mm}$ diameter module. After processing, the diets were packed into plastic zipper bags and stored at $20^{\circ} \mathrm{C}$ until used.

Sample collection and analysis. At the end of the trial, six fish were sampled at random from each replicate and anesthetized by dipping in $75 \mu \mathrm{l} / \mathrm{L}$ of eugenol oil suspension in water for 30s; blood samples were then collected from the caudal vein of each anesthetized fish. After being kept at $4^{\circ} \mathrm{C}$ for $30 \mathrm{~min}$, the blood samples were centrifuged at $3500 \mathrm{rpm}$ for $10 \mathrm{~min}$ at $4^{\circ} \mathrm{C}$, and the supernatant serum collected and stored at $-80^{\circ} \mathrm{C}$ before analysis of serum lipid levels. After collecting blood samples, the fish from each replicate were killed in an ice bath for liver samples. The livers from each replicate were pooled and homogenized in 10 volumes $(\mathrm{v} / \mathrm{w})$ of ice-cold normal saline $(0.68 \%)$. The homogenates were centrifuged at $10,000 \mathrm{rpm}$ for $15 \mathrm{~min}$ at $4^{\circ} \mathrm{C}$ and the supernatants with the enzyme extracts were collected and stored at $-80^{\circ} \mathrm{C}$ until assayed.

Analyses of the proximate composition of basal diets, lipid levels of whole fish body and liver were performed according to the methods of Zhai et al. (2014). The total cholesterol (TC), triglyceride (TG), low-density lipoprotein cholesterol (LDL-C), highdensity lipoprotein cholesterol (HDL-C) in serum were determined with commercial clinical investigation kits (Nanjing Jiancheng Bioengineering Institute, Nanjing, China). All these parameters were analyzed using an automatic biochemical analyzer (Hitachi 7020, Tokyo, Japan). The levels of fatty acid synthetase (FAS) and acetyl CoA carboxylase $(A C C)$, and the activities of hepatic lipase $(H L)$, and lipoprotein lipase (LPL) were measured according to methods of Zhai et al. (2015a).

Statistical analysis. The results are presented as means \pm SD of four replicates. Statistical analysis was performed with SPSS 11.5 statistical software (SPSS, Chicago, IL, USA). Data from each treatment group were subjected to one-way analysis of variance (ANOVA), Duncan's multiple range test was used to compare the mean values among the treatment groups. Level of significance was $\mathrm{P}<0.05$.

\section{Results}

Lipid levels in serum. The serum lipid levels of orange-spotted grouper juveniles fed diets with different surfactin levels are shown in table 1.

Compared with the control group, TC and LDL-C levels in all other groups significantly decreased $(P<0.05)$. The TG levels of 25,50 , and $100 \mathrm{mg} / \mathrm{kg}$ surfactin supplemented groups also significantly decreased $(P<0.05)$. The HDL-C levels in all groups with dietary surfactin supplementation significantly increased $(P<0.05)$. A significant difference of TC level was only found between $100 \mathrm{mg} / \mathrm{kg}$ surfactin group and $200 \mathrm{mg} / \mathrm{kg}$ surfactin group $(P<0.05)$, the differences of TG levels among all surfactin groups were not significant. $(P>0.05)$. 
Table 1. Serum lipid levels of orange-spotted grouper juveniles fed diets with different levels of surfactin supplementation

\begin{tabular}{lllll}
\hline $\begin{array}{l}\text { Dietary surfactin level } \\
(\mathrm{mg} / \mathrm{kg})\end{array}$ & $\begin{array}{l}T C \\
(\mathrm{mmol} / \mathrm{L})\end{array}$ & $\begin{array}{l}T G \\
(\mathrm{mmol} / \mathrm{L})\end{array}$ & $\begin{array}{l}\mathrm{LDL}-\mathrm{C} \\
(\mathrm{mmol} / \mathrm{L})\end{array}$ & $\begin{array}{l}H D L-C \\
(\mathrm{mmol} / \mathrm{L})\end{array}$ \\
\hline 0 & $2.10 \pm 0.02^{\mathrm{c}}$ & $0.43 \pm 0.06^{\mathrm{b}}$ & $0.50 \pm 0.02^{\mathrm{c}}$ & $0.48 \pm 0.04^{\mathrm{a}}$ \\
25 & $1.69 \pm 0.24^{\mathrm{ab}}$ & $0.20 \pm 0.02^{\mathrm{a}}$ & $0.25 \pm 0.02^{\mathrm{a}}$ & $0.87 \pm 0.04^{\mathrm{b}}$ \\
50 & $1.71 \pm 0.05^{\mathrm{ab}}$ & $0.19 \pm 0.06^{\mathrm{a}}$ & $0.24 \pm 0.02^{\mathrm{a}}$ & $1.07 \pm 0.06^{\mathrm{c}}$ \\
100 & $1.58 \pm 0.01^{\mathrm{a}}$ & $0.21 \pm 0.03^{\mathrm{a}}$ & $0.18 \pm 0.01^{\mathrm{a}}$ & $1.01 \pm 0.08^{\mathrm{c}}$ \\
150 & $1.79 \pm 0.15^{\mathrm{ab}}$ & $0.30 \pm 0.05^{\mathrm{ab}}$ & $0.24 \pm 0.02^{\mathrm{a}}$ & $0.98 \pm 0.04^{\mathrm{bc}}$ \\
200 & $1.86 \pm 0.09^{\mathrm{b}}$ & $0.31 \pm 0.05^{\mathrm{ab}}$ & $0.43 \pm 0.02^{\mathrm{b}}$ & $0.87 \pm 0.04^{\mathrm{b}}$ \\
\hline
\end{tabular}

$\mathrm{TC}=$ total cholesterol; $\mathrm{TG}=$ triglyceride; $\mathrm{LDL}-\mathrm{C}=$ low-density lipoprotein cholesterol; $\mathrm{HDL}-\mathrm{C}=$ high-density lipoprotein cholesterol.

${ }^{\mathrm{abc}}$ Values within the same column with different superscripts were significantly different at $\mathrm{P}<0.05$ level.

Lipid levels in whole fish and liver. Lipid levels in whole fish and liver of orangespotted grouper juveniles fed diets with different surfactin levels are shown in table 2.

The lipid levels of whole fish in all groups with dietary surfactin supplementation decreased significantly $(P<0.05)$ compared with the control group. The liver lipid levels of $100 \mathrm{mg} / \mathrm{kg}$ and $150 \mathrm{mg} / \mathrm{kg}$ surfactin supplementation groups were significantly higher than the control group $(P<0.05)$. Lipid levels of whole fish in the dietary surfactin supplementation groups were similar $(P>0.05)$. Liver lipid levels in the $100 \mathrm{mg} / \mathrm{kg}$ surfactin group were significantly lower than in the S25, S50, and S150 mg/kg groups $(P<0.05)$. The liver lipid level of $150 \mathrm{mg} / \mathrm{kg}$ surfactin group was significantly lower than that in the $25 \mathrm{mg} / \mathrm{kg}$ surfactin group $(P<0.05)$. No significant differences were found among the other surfactin supplementation groups ( $P>0.05)$.

Table 2 Lipid levels in whole fish and liver of orange-spotted grouper juveniles fed diets with different levels of surfactin supplementation

\begin{tabular}{lll}
\hline Dietary surfactin level $(\mathrm{mg} / \mathrm{kg})$ & Lipid level in whole fish $(\%)$ & Lipid level in liver(\%) \\
\hline 0 & $26.26 \pm 0.60^{\mathrm{b}}$ & $25.64 \pm 0.67^{\mathrm{c}}$ \\
25 & $24.60 \pm 0.74^{\mathrm{a}}$ & $25.07 \pm 0.70^{\mathrm{c}}$ \\
50 & $24.64 \pm 0.92^{\mathrm{a}}$ & $24.79 \pm 20.84^{\mathrm{bc}}$ \\
100 & $23.68 \pm 0.50^{\mathrm{a}}$ & $23.37 \pm 0.57^{\mathrm{a}}$ \\
150 & $24.00 \pm 0.88^{\mathrm{a}}$ & $23.67 \pm 0.98^{\mathrm{ab}}$ \\
200 & $24.06 \pm 0.95^{\mathrm{a}}$ & $24.96 \pm 0.42^{\mathrm{bc}}$ \\
\hline
\end{tabular}

${ }^{a b c}$ Values within the same column with different superscripts were significantly different at $\mathrm{P}<0.05$ level.

Lipid metabolism enzyme in liver. Lipid metabolism enzyme levels/activities in liver of orange-spotted grouper juveniles fed diets with different surfactin levels were shown in table 3.

FAS levels of $100 \mathrm{mg} / \mathrm{kg}$ surfactin group was significantly lower $(P<0.05)$ compared to the control group, the., No significant differences in ACC levels were found among all groups $(P>0.05)$. The activities of $\mathrm{HL}$ and $\mathrm{LPL}$ of $100 \mathrm{mg} / \mathrm{kg}$ surfactin group were significantly higher $(P<0.05)$. There were no significant differences among the other groups $(P>0.05)$.

Table 3. Lipid metabolism enzyme levels/activities in liver of orange-spotted grouper juveniles fed diets with different levels of surfactin supplementation

\begin{tabular}{lllll}
\hline $\begin{array}{l}\text { Dietary surfactin level } \\
(\mathrm{mg} / \mathrm{kg})\end{array}$ & $\begin{array}{l}\text { FAS } \\
(\mathrm{nmol} / \mathrm{L})\end{array}$ & $\begin{array}{l}A C C \\
(\mathrm{ng} / \mathrm{L})\end{array}$ & $\begin{array}{l}H L \\
(\mathrm{U} / \mathrm{mg} \mathrm{prot})\end{array}$ & $\begin{array}{l}\mathrm{LPL} \\
(\mathrm{U} / \mathrm{mg} \mathrm{prot})\end{array}$ \\
\hline 0 & $42.57 \pm 2.36^{\mathrm{b}}$ & $1609.51 \pm 24.22^{\mathrm{a}}$ & $0.57 \pm 0.07^{\mathrm{a}}$ & $0.45 \pm 0.05^{\mathrm{a}}$ \\
25 & $42.46 \pm 1.53^{\mathrm{b}}$ & $1601.29 \pm 73.36^{\mathrm{a}}$ & $0.67 \pm 0.03^{\mathrm{ab}}$ & $0.46 \pm 0.03^{\mathrm{a}}$ \\
50 & $37.35 \pm 2.77^{\mathrm{ab}}$ & $1643.29 \pm 46.85^{\mathrm{a}}$ & $0.63 \pm 0.05^{\mathrm{a}}$ & $0.48 \pm 0.03^{\mathrm{a}}$ \\
100 & $35.01 \pm 3.71^{\mathrm{a}}$ & $1646.13 \pm 30.72^{\mathrm{a}}$ & $0.75 \pm 0.07^{\mathrm{b}}$ & $0.57 \pm 0.06^{\mathrm{b}}$ \\
150 & $38.58 \pm 3.11^{\mathrm{ab}}$ & $1624.45 \pm 43.01^{\mathrm{a}}$ & $0.67 \pm 0.08^{\mathrm{ab}}$ & $0.49 \pm 0.05^{\mathrm{a}}$ \\
200 & $39.14 \pm 2.38^{\mathrm{ab}}$ & $1604.28 \pm 36.88^{\mathrm{a}}$ & $0.58 \pm 0.08^{\mathrm{a}}$ & $0.45 \pm 0.03^{\mathrm{a}}$ \\
\hline
\end{tabular}

FAS=Fatty acid synthetase; $A C C=$ acetyl $C o A$ carboxylase, $H L=$ hepatic lipase; $L P L=$ poprotein lipase.

${ }^{a b c}$ Values within the same column with different superscripts were significantly different at $P<0.05$ level. 


\section{Discussion}

The results of our study showed that dietary surfactin supplementation could decrease levels of serum TG, TC and LDL-C and increase HDL-C levels in orange-spotted grouper. This is consistent with results of previous studies with other aquatic species. In a tilapia study where dietary surfactin levels were 50,100, and $200 \mathrm{mg} / \mathrm{kg}$, TC levels of 50 and $100 \mathrm{mg} / \mathrm{kg}$ supplementation groups, and TG levels of all surfactin supplementation groups, were significantly lower than those of control group (Zhai et al., 2015a). Data in our previous study on the Chinese soft-shelled turtle, with dietary surfactin levels being 5, 10, and $20 \mathrm{mg} / \mathrm{kg}$, showed that the TC, TG and LDL-C levels in all groups decreased significantly, while HDL-C levels of all treatment groups were similar (Zhai et al., 2015b). The decreasing effect of surfactin as emulsifier on blood lipid levels was also found in terrestrial animals. $400 \mathrm{mg} / \mathrm{kg}$ body weight lipopeptides (a mixture of surfactin and fengycin) was found to decrease the serum TC level of the mice (Ayed et al. 2015). Lipopeptide SPB1 biosurfactant (the mixture of surfactin and its analogs) had an effect on TC levels of mice in a dose-dependent manner, and decreased TC levels at its normal level (when injecting $47.5 \mathrm{mg} / \mathrm{kg}$ ) (Sahnoun et al. 2014). While the results of surfactin in a weaned pig study were different from the above reports, the surfactin supplementation increased the TG and HLD-C levels, decreased the TC levels and had no effect on LDL-C levels (Du et al., 2011). Surfactin is known for its excellent surface activity and self-assembling properties and acts as an emulsifier in industrial food applications. It behaves as a powerful biosurfactant, which is to be expected given the amphiphilic nature of the lipopeptide, with a polar amino acid head and a hydrocarbon chain (Gao et al., 2013; Chen et al., 2015; Sanjukta and Rai, 2016).

Our results showed that dietary surfactin supplementation had a lowering effect on lipid levels in whole fish and liver. Knowledge regarding the effect of dietary surfactin supplementation on the composition of whole body and liver of fish is scarce but the effect of other emulsifiers on lipid levels of whole body or liver have been reported in other fish species. The emulsifier from bile acid could decrease the whole body lipid level or liver lipid level. The lipid levels of both whole body and liver were found to decrease with $1.5 \%$ bile acid dietary supplementation in turbot (Scophthalmus maximus L.) (Sun et al., 2015). Lipid levels in liver also decreased in studies of finless eel (Monopterus albus) with dietary $5 \%$ lecithin supplementation, and catfish (Pangasius sutchi) with $3 \%$ phospholipids in the diet (Yuan et al., 2007; Ma et al., 2015).

In fish, the liver plays a central role in lipid metabolism, lipid accumulation in fish results from the balance between synthesis of fatty acids (lipogenesis) and fat catabolism via $\beta$-oxidation (lipolysis), and several key enzymes are involved in these metabolic processes (Chen et al., 2013). De novo fatty acid synthesis is catalyzed by a sequential action of two enzymatic systems: ACC and the multienzyme complex FAS. There is considerable evidence that LPL and HL are important factors in lipolysis; both LPL and HL promote the uptake of lipoproteins by the liver in fish and play a pivotal role in regulating lipid content in fish (Albalat et al., 2007; Tian et al., 2013). In the present study, FAS levels decreased and the $\mathrm{HL}$ and $\mathrm{LPL}$ activities increased with dietary surfactin supplementation, while $100 \mathrm{mg} / \mathrm{kg}$ surfactin supplementation could significantly decrease the FAS levels and increase HL and LPL activity. Similar results were also reported in the tilapia study; FAS activity of surfactin supplementation groups (50, 100, and $200 \mathrm{mg} / \mathrm{kg}$ supplementation groups) significantly decreased, and ACC activity was not affected by surfactin supplementation. HL and LPL activity significantly increased, and no significant differences of those two enzymes were found among all surfactin supplementation groups (Zhai et al., 2015a).

Changes of lipid in serum, whole fish, and liver, of orange-spotted grouper might be related to changes of levels and activities of lipid metabolism enzymes in the liver. The lipid lowering effect of dietary surfactin supplementation did not improve with increasing dietary surfactin levels. Our results indicated that the lipid inhibiting effect was obvious only with certain surfactin levels This phenomenon might be related to the surface active properties of surfactin, which is the base to many biological activities that are highly dependent on the surfactin concentration. There is a threshold concentration 
of surfactin in the bilayer for its solubilization (Seydlova and Svobodova, 2008; Chen et al., 2015). Further study is needed to discover the detailed mechanisms of surfactin in lowering lipids in orange-spotted grouper.

In summary, the present study showed that the appropriate surfactin supplementation level in diet of orange-spotted grouper juvenile might decrease the lipid levels in serum, whole fish, and liver, in orange-spotted grouper by regulating the levels or activity of lipid metabolism enzymes in the liver.

\section{Acknowledgements}

The financial support provided by Special Project of International Science and Technology Cooperation and Exchange of Ministry of Science and Technology (Grant No.2014DFT30150), Science and Technology Major/Special Project of Fujian Province (No.2016NZ0001-3), and Community Project of Mr. Yang Sheng's Student (No.2016A30010) are gratefully acknowledged.

\section{References}

Albalat A., Saera-Vila A., Capilla E., Gutierrez J., Perez-Sanchez J., Navarro I., 2007.Insulin regulation of lipoprotein lipase (LPL) activity and expression in gilthead sea bream (Sparus aurata). Comp. Biochem. Physiol., 148B:151-159.

Ayed H.B., Nasri R., Jemil N., Amor I.B., Gargouri J., Hmidet N., Nasri M., 2015. Acute and sub-chronic oral toxicity profiles of lipopeptides from Bacillus mojavensis A21 and evaluation of their in vitro anticoagulant activity. Chem.-Biol. Interact., 236: 1-6.

Caballero M.J., Lopez-Calero G., Socorro J., Roo F.J., Izquierdo M.S., Fernandez A.J., 1999. Combined effect of lipid level and fishmeal quality on liver histology of gilthead seabream (Sparus aurata). Aquaculture, 179:277-290.

Chen Q.L., Gong Y., Luo Z., Zheng J.L., Zhu Q.L.,2013. Differential effect of waterborne cadmium exposure on lipid metabolism in liver and muscle of yellow catfish Pelteobagrus fulvidraco. Aquat. Toxicol., 142:380-386.

Chen W C, Juang RS, Wei YH., 2015.Applications of a lipopeptide biosurfactant, surfactin, produced by microorganisms.Biochem. Eng. J., 103:158-169.

Coutteau P., Geurden I., Camara M.R., Bergot P., Sorgeloos P., 1997. Review on the dietary effects of phospholipids in fish and crustacean larviculture. Aquaculture, 155(1):149-164.

Craig S.R., Washburn B.S., Gatlin III D.M., 1999. Effects of dietary lipids on body composition and liver function in juvenile red drum, Sciaenops ocellatus. Fish Physiol. Biochem., 21(3): 249-255.

Du H.M., Qi G.Z., Wang J.J., Zhang X.H., Lu Z.X., Wang T.,2011. Effects of antimicrobial lipopeptides on performance,intestinal microflora and blood biochemical parameters in weaned pigs. J. Chinese Cereals and Oils Assoc., 26(5):76-82.

Gao, Z., Zhao, X., Lee, S., Li, J., Liao, H., Zhou, X., Wu, J., Qi, G., 2013. WH1fungin a surfactin cyclic lipopeptide is a novel oral immunoadjuvant. Vaccine, 31(26): 27962803.

Kim S.K., Matsunari H., Takeuchi T., Yokoyama M., Murata Y., Ishihara K., 2007. Effect of different dietary taurine levels on the conjugated bile acid composition and growth performance of juvenile and fingerling Japanese flounder Paralichthys olivaceus. Aquaculture, 273(4):595-601.

Li Y., Liu X., Zhang Y., Ma X., Lin H., 2013. Effects of cysteamine on mRNA levels of growth hormone and its receptors and growth in orange-spotted grouper (Epinephelus coioides). Fish Physiol. Biochem., 39(3):605-613.

Liu J., Zou A.H, Mu B.Z., Surfactin effect on the physicochemical property of PC liposome.Colloids and Surfaces A: Physicochem. Eng. Asp., 361(1):90-95.

Ma Y.Q., Huang K., Dai X.L., Yu D., Chen T., 2015. Effect of dietary phospholipids level on lipid metabolism in liver of catfish (Pangasius sutchi). Feed Ind., 36(6):31-35.

Martinez-Rubio L., Wadsworth S., Vecino J.L.G., Bell J.G., Tocher D.R., 2013. Effect of dietary digestible energy content on expression of genes of lipid metabolism and LC-PUFA biosynthesis in liver of Atlantic salmon (Salmo salar L.). Aquaculture, 384:94103. 
Pierre S., Gaillard S., Prévot-D'Alvise N., Aubert J., Rostaing-Capaillon O., Leung-Tack D., Grillasca J.P.,2008.Grouper aquaculture: Asian success and Mediterranean trials. Aquat. Conserv. Mar. Freshw. Ecosyst.,18(3):297-308.

Sahnoun R, Mnif I, Fetoui H, Gdoura R., Chaabouni K., Makni-Ayadi F.,Ghribi D., 2014. Evaluation of Bacillus subtilis SPB1 lipopeptide biosurfactant toxicity towards mice. Int. J. Pept. Res. Ther., 20(3): 333-340.

Sanjukta S., Rai A.K., 2016. Production of bioactive peptides during soybean fermentation and their potential health benefits. Trends in Food Sci. Tech., 50:1-10..

Seydlova G., Svobodova J., 2008. Review of surfactin chemical properties and the potential biomedical applications. Cent. Eur. J. Med., 3(2): 123-133.

Sun J.Z., Wang J.Y., Ma J.J.,Li B.S.,Hao T.T.,Sun Y.Z.,Zhang L.M., 2014. Effects of dietary bile acids on growth, body composition and lipid metabolism of juvenile turbot (scophthalmus maximus) at different lipid levels. Oceanologia Et Limnologia Sinica, 45(3):617-625.

Tani Y, Mizuno S, Sumioka M, Furuichi Y., Ohshima Y., Fushimi T., Kakinuma A., 2006. Synergistic effects of surfactin and natto in lowering the serum and liver lipid levels of rats fed a high-fat diet. J. Japanese Soc. Nutr. Food Sci.,59:85-98.

Tocher D.R., 2003. Metabolism and functions of lipids and fatty acids in teleost fish. Rev. Fish. Sci., 11:107-184.

Yuan H.W., Yang D.Q., 2007. Effect of dietary lecithin supplementation on the lipid lelvels in liver and muscle of finless eel (Monopterus albus). Reserv. Fish., 27(4):102103.

Zhai S.W., Li J., Sun X.W., 2015a. Effects of surfactin supplementation on growth performance, serum biochemical indexes and lipid metabolism of genetically improved farmed tilapia (Oreochromis niloticus). Chinese J. Anim. Nutr., 27(12): 3959-3967.

Zhai S.W., Lu J.J., Chen X.H., 2014. Effects of dietary grape seed proanthocyanidins on growth performance, some serum biochemical parameters and body composition of tilapia (Oreochromis niloticus) fingerlings. Ital. J. Anim. Sci., 13:536-540.

Zhai S.W., Shi Q.C., Sun P.X., Lu P., Guo Q.X., 2015b. Effect of dietary surfactin supplementation on weight gain rate and blood biochemical parameters of juvenile Chinese soft-shelled turtle (Pelodiscus sinensis). Feed China, (22):39-41.

Zhai S.W., Shi Q.C., Wang N., Lu P., Guo Q.X., 2016. Effects of antimicrobial lipopeptides surfactin supplementation on growth performance and intestinal digestive enzyme activities of juvenile Chinese soft-shelled turtle (Pelodiscus sinensis). Feed Ind., $37(2): 30-33$. 